\title{
Usefulness of hemoglobin examination in gingival crevicular fluid during supportive periodontal therapy to diagnose the pre-symptomatic state in periodontal disease
}

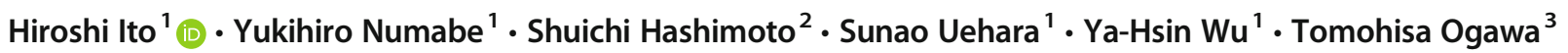

Received: 24 January 2020 / Accepted: 5 June 2020 / Published online: 15 June 2020

(C) The Author(s) 2020

\begin{abstract}
Objectives The absence of bleeding on probing (BOP) is a good predictor of disease stability. This study investigated whether detection of hemoglobin $(\mathrm{Hb})$ in gingival crevicular fluid $(\mathrm{GCF})$ indicates minute signs of periodontal disease, even in BOP $(-)$ cases.

Materials and methods GCF was collected from gingival sulci of 152 sound maxillary and mandibular teeth from 76 patients who had entered supportive periodontal therapy (SPT) using the split-mouth design. As clinical parameters, plaque index, GCF amount, gingival index, probing depth (PD), clinical attachment level, BOP, and alveolar bone resorption ratio were then recorded. As biochemical parameters, $\mathrm{Hb}$ amount, alkaline phosphatase (ALP) activity, and protein amount in GCF were measured. Periodontal conditions of diseased sites (PD $\geq 4 \mathrm{~mm}, \mathrm{BOP}(+))$ and healthy sites (PD $\leq 4 \mathrm{~mm}, \mathrm{BOP}(-)$ ) were further classified into two groups using the $\mathrm{Hb}$ cutoff value determined by $\mathrm{PD}$ and $\mathrm{BOP}$ and analyzed.

Results Despite being healthy, ALP activity and protein amount in sulci of the group with $\mathrm{Hb}$ level greater than the cutoff value were significantly higher than those in the group with $\mathrm{Hb}$ level less than the cutoff value $(P<0.01)$.

Conclusions This study indicates that $\mathrm{Hb}$ examination is a promising candidate marker of pre-symptomatic periodontal disease because $\mathrm{Hb}$ presence in GCF suggests slight tissue damage, even in healthy sites defined as BOP (-).

Clinical relevance $\mathrm{Hb}$ examination of GCF is a powerful diagnostic tool for pre-symptomatic diagnosis of periodontal disease.
\end{abstract}

Keywords Gingival crevicular fluid $\cdot$ Periodontitis $\cdot$ Hemoglobin $\cdot$ Supportive periodontal therapy

\section{Introduction}

Important items during the period of supportive periodontal therapy (SPT) are the accurate diagnosis of periodontitis and prompt response corresponding to symptoms in order to prevent the recurrence of periodontal disease [1, 2]. Both probing depth (PD) measurement and bleeding on probing (BOP) examination are presently recognized worldwide as extremely effective parameters for assessing

Hiroshi Ito

hiroshi@tky.ndu.ac.jp

1 Department of Periodontology, School of Life Dentistry at Tokyo, The Nippon Dental University, Tokyo, Japan

2 The Nippon Dental University, Tokyo, Japan

3 General Dentistry, The Nippon Dental University Hospital, Tokyo, Japan periodontal disease and recurrence [3-5]. However, these measurements and examinations are not only inspections requiring delicate skills, but also tests in which the burden on the patient increases due to pain associated with the examination according to the condition of deteriorated periodontal disease [6]. Furthermore, the BOP test has a higher negative predictive value than positive predictive value [7]. Therefore, we focused on gingival crevicular fluid (GCF), which can be painlessly sampled, as a candidate test item to supplement PD measurement and BOP examination in the SPT phase and analyzed its components [8-10].

BOP examination visually judges the presence or absence of bleeding after PD measurement and evaluates periodontal tissue condition $[11,12]$. In contrast, we hypothesized that the detection of hemoglobin $(\mathrm{Hb})$, which is already present in GCF by invisible inflammatory bleeding, is effective for pre-disease diagnosis of periodontal disease $[9,10]$. Therefore, we measured the $\mathrm{Hb}$ 
amount in GCF, which is an indicator of bleeding in the periodontal pocket, and analyzed the correlation between $\mathrm{Hb}$ amount and other periodontal tissue examinations. We reported that $\mathrm{Hb}$ amount in GCF collected from 401 pockets in 184 SPT patients correlates well with assessments of clinical parameters (e.g., plaque index (PlI), GCF amount, PD, clinical attachment level (CAL), gingival index (GI), and BOP) for periodontal condition [10]. As a result, we found that $\mathrm{Hb}$ examination could be a helpful test item, which complements conventional periodontal tissue inspections $[9,10]$.

However, it is unclear whether the presence of $\mathrm{Hb}$ in GCF could be a marker of periodontal tissue damage. Therefore, when BOP is negative, it is not known whether $\mathrm{Hb}$ in GCF is present at the site where there is a possibility of periodontal tissue damage. In particular, we hypothesized that $\mathrm{Hb}$ in $\mathrm{GCF}$, which can be expressed in the case of BOP (-), is effective for detecting the presymptomatic state in periodontal disease.

In the present study, we used a split-mouth design to eliminate differences between individuals in periodontal tissue examination and increase reliability. GCF was simultaneously collected from both healthy and diseased sites in the same oral cavity in each patient, and the components in GCF were analyzed [13]. We then compared each clinical parameter (PII, GCF amount, GI, PD, CAL, and alveolar bone resorption (ABR) ratio) and $\mathrm{Hb}$ amount, in addition to ALP activity and protein amount as biochemical parameters in GCF that increase with the onset of periodontitis [8, 14-19]. Finally, we checked for correlations between the examinations of conventional clinical and biochemical parameters and the examination of $\mathrm{Hb}$. We believe that the present evaluation of the usefulness of $\mathrm{Hb}$ inspection in GCF in periodontal diagnosis confirms that the $\mathrm{Hb}$ amount can be used to identify the pre-symptomatic state in periodontal disease.

\section{Materials and methods}

\section{Experimental design}

This study was a cross-sectional study, using a splitmouth design. Patients were randomized into one of two groups. The study was prepared according to the STROBE guidelines.

\section{Patients}

Patients were 76 nonsmokers (39 men, 37 women; mean age $63.4 \pm 10.8$ years) who were receiving SPT at a periodontal specialty clinic at the Nippon Dental University Hospital (mean SPT period, 5.2 \pm 7.1 years). The history of periodontal treatment was $2.4 \pm 1.5$ years during the period of active periodontal treatment. GCF was collected from 96 patients using the split-mouth design. Among these patients, there were 76 healthy and diseased site pairs. Thus, 20 patients without both healthy and diseased sites were excluded from the analyses.

Specifically, in order to confirm that we can shift the SPT period, we performed the periodontal tissue examination including ABR rate determined by the X-ray image. From the latest periodontal tissue examination including the X-ray image and visual examination of the gingival tissue with marginal gingival position immediately before GCF collection, we predicted healthy and diseased sites and collected GCF randomly. As a result, out of 96 patients, 76 patients had both healthy and diseased sites.

In addition, Table 1 shows the classification of periodontal disease [20] for 76 patients.

Inclusion criteria were that the patient had at least 12 remaining natural teeth (number of naturally remaining teeth, $22.4 \pm 4.0$ ) and was generally healthy. Exclusion criteria were as follows: (1) patients with diabetes, immune disorders, liver disease, heart disease, or osteoporosis; (2) females who were pregnant or taking birth control pills; (3) patients who had received antimicrobial therapy for the past 3 months; and (4) patients who did not provide consent to participate in this study. Prior to commencing this study, patients received an explanation of the study and were asked to provide written consent.

This study was conducted in accordance with the Helsinki Declaration of 1975, as revised in 2013, with approval from the ethics committee of the Nippon Dental University Hospital (Approval Nos. NDU-T 2017-12 and NDUH-RINRI2018-07).

\section{GCF collection and preparation}

GCF was sampled from a single tooth corresponding to each of the following clinical parameters on both healthy and diseased sites of the same patient. In other words, we compared clinical and biochemical parameters in GCF for both healthy and diseased sites from SPT using the splitmouth design to exclude the possibility of individual differences due to different oral environments.

Criteria for sampling sites were as follows: for healthy sites, PD $\leq 4 \mathrm{~mm}$ and BOP (-) and, for diseased sites, PD $\geq 4 \mathrm{~mm}$ and BOP (+) [7, 21-23]. Abutment teeth for partial dentures, full crowns, and implants were excluded.

In order to collect GCF, after measuring the PII [24], the pocket was simply dried using cotton rolls and air, and the overlying plaque was removed as much as possible. Subsequently, a blotting paper strip (PerioPaper ${ }^{\circledR}$, Oraflow Inc., Plainview, NY, USA) was inserted into 
Table 1 Classification of periodontitis in patients $(n=76)$

\begin{tabular}{|c|c|c|c|c|c|c|c|c|c|c|c|c|}
\hline \multirow{2}{*}{$\begin{array}{l}\text { Stage } \\
\text { Grade }\end{array}$} & \multicolumn{3}{|l|}{ I } & \multicolumn{3}{|l|}{ II } & \multicolumn{3}{|l|}{ III } & \multicolumn{3}{|c|}{ IV } \\
\hline & A & $\mathrm{B}$ & $\mathrm{C}$ & A & $\mathrm{B}$ & $\mathrm{C}$ & $\mathrm{A}$ & $\mathrm{B}$ & $\mathrm{C}$ & A & $\mathrm{B}$ & $\mathrm{C}$ \\
\hline Localized periodontitis & - & - & - & 2 & 13 & - & - & 1 & 2 & - & - & - \\
\hline Generalized periodontitis & - & - & - & - & 3 & 1 & - & 14 & 5 & - & 20 & 15 \\
\hline
\end{tabular}

the pocket until resistance was felt, and GCF was collected with paper for $30 \mathrm{~s}$. The process for collecting GCF was repeated three times using three paper strips. The amount of GCF collected was measured using a calibrated unit (Periotron ${ }^{\circledR} 8000$, Oraflow Inc.) and expressed as microliters $(\mu \mathrm{L})$. The three paper strips used to sample the GCF were immediately soaked in $350 \mu \mathrm{L}$ of phosphate-buffered saline (PBS), stirred for $5 \mathrm{~min}$, and centrifuged for $5 \mathrm{~min}$ at $10,000 \mathrm{rpm}$. The supernatant was dispensed for biochemical analysis. The recovery rate of all biochemical parameters into the solvent from the paper strips that collected GCF was $98 \%$ or greater. If bleeding happened by insertion of the paper strip, the GCF sample was considered to be contaminated with blood and was excluded. Each GCF sample was stored at $-80{ }^{\circ} \mathrm{C}$ until further analysis $[9,10,13]$.

\section{Measurement of clinical parameters}

All subjects underwent periodontal tissue examination by a specialist periodontist (HI), who is certified by the Japanese Society of Periodontology (Registration No. 147). After calibration, a $95.6 \%$ concordance rate $(n=12)$ within $1 \mathrm{~mm}$ for PD and CAL measurements between the first and second recording with a 24-h interval was reached.

To prevent blood contamination from the periodontal tissue examination during GCF collection, GCF was collected after PII measurement. Then, GI [25], PD, CAL, BOP [12], and ABR ratio were assessed after GCF sampling. In the X-ray image used to measure the ABR ratio, the long cone technique was used for standardization. PD and CAL were measured using a pocket probe (Williams Probe, Hu-Friedy Inc., Chicago, IL, USA) with standardized force ranging 20-25 g [4]. PD was measured to the nearest millimeter $(\mathrm{mm})$. Finally, BOP was recorded. To measure the ABR ratio, we used the modified ruler by Schei et al. [26]; the ABR ratio was measured from the tooth root length and alveolar bone height obtained from the transmitted dental X-ray image of each site.

Finally, 152 GCF samples from 76 patients were collected from September 2015 to October 2016 at the Nippon Dental University Hospital and included in subsequent analyses.

\section{Analysis of biochemical parameters}

\section{Biochemical parameters included $\mathrm{Hb}$ amount, ALP activity, and protein amount}

$\mathrm{Hb}$ amount in GCF was measured using an $\mathrm{Hb}$ detection kit (Check-Line Hemo®, Wakamoto, Tokyo, Japan) using immunochromatography (IC) with a human $\mathrm{Hb}$ monoclonal antibody $[27,28]$. A $10-\mu \mathrm{L}$ sample of PBS extraction was added to $40 \mathrm{~mL}$ of IC solvent containing bovine serum albumin, polysorbate 20 (Tween 20, Sigma-Aldrich, St. Louis, MO, USA), and sodium acid in neutral PBS, and then, $\mathrm{Hb}$ in $50 \mu \mathrm{L}$ of the solution was developed at $23{ }^{\circ} \mathrm{C}$ for $15 \mathrm{~min}$ with IC paper. The developed IC paper was then air-dried overnight, and the amount of human $\mathrm{Hb}$ monoclonal antibody tinged with red latex in the chromatogram was measured by a densitometer (GS-800 Calibrated Densitometer PC system, Bio-Rad, Tokyo, Japan). The pocket site was defined as positive for $\mathrm{Hb}$ at $\geq 1 \mathrm{ng} /$ pocket $\mathrm{Hb}$.

ALP activity in the GCF sample was expressed as $\mu \mathrm{U} /$ pocket using the measurement conforming to the BesseyLowry method [14]. The enzyme reaction was performed with p-nitrophenyl phosphate, and resultant p-nitrophenol was measured using a microplate reader at $405 \mathrm{~nm}$.

To measure protein amount in the GCF sample, we utilized the protein assay kit $\left(\mathrm{BCA}^{\mathrm{TM}}\right.$ Protein Assay Kit, Thermo Fisher Scientific, Waltham, MA, USA), and values are expressed as $\mu \mathrm{g} /$ pocket.

\section{Statistical analysis}

Clinical and biochemical parameters are expressed as means and standard deviation (SD). All analyses were performed using statistical software (PASW 18.0.0, SPSS, Chicago, IL, USA).

The Kolmogorov-Smirnov normality test was used to determine normality, and none of the clinical and biochemical parameters exhibited normal distribution $(P<0.01)$.

We used the Mann-Whitney $U$ test to compare healthy and diseased sites. Correlations between clinical and biochemical parameters were examined using Spearman's correlation coefficient. In addition, based on criteria for healthy and diseased sites, we prepared a cutoff value for $\mathrm{Hb}$ amount using 
the receiver operating characteristic (ROC) curve and Youden index.

Healthy site and diseased site groups were respectively reclassified into two groups of less than the cutoff value of $\mathrm{Hb}$ amount in GCF (low-Hb, L-Hb) and greater than the cutoff value of $\mathrm{Hb}$ amount in $\mathrm{GCF}$ (high- $\mathrm{Hb}, \mathrm{H}-\mathrm{Hb}$ ). Consequently, these gingival sulcus sites were divided into four groups: healthy $\mathrm{L}-\mathrm{Hb}$ group, healthy $\mathrm{H}-\mathrm{Hb}$ group, diseased L-Hb group, and diseased $\mathrm{H}-\mathrm{Hb}$ group corresponding to periodontal disease progression. After Kruskal-Wallis analysis of the four groups, mutually significant differences among the four groups were confirmed with the Steel-Dwass test as a post hoc analysis. Statistical significance was set at $P<0.05$. The workflow of this study is shown in Fig. 1.

Interquartile range analysis was performed for all clinical and biochemical parameters.

Power calculations indicated a sample size of 64 patients and $128 \mathrm{GCF}$ samples to be necessary (alpha, 0.05; power, 0.8). We thus enrolled 76 patients and collected $152 \mathrm{GCF}$ samples to account for any potential complications (e.g., consent withdraw or insufficient sample volume).

\section{Results}

\section{Comparison of clinical and biochemical parameters between healthy and diseased sites in the same oral cavity}

Table 2 shows clinical parameters (PII, GCF amount, GI, PD, $\mathrm{CAL}, \mathrm{BOP}$, and $\mathrm{ABR}$ ratio) and biochemical parameters ( $\mathrm{Hb}$ amount, ALP activity, and protein amount). All clinical and biochemical parameters were significantly higher in diseased sites $(n=76)$ than in healthy sites $(n=76)(P<0.01)$. In particular, $\mathrm{Hb}$ amount in GCF samples from 152 sites ranged 1-204 ng/pocket.

\section{Correlation between $\mathrm{Hb}$ amount and other parameters in GCF}

A significant correlation was observed between every parameter (PII, GCF amount, GI, PD, CAL, BOP, ABR ratio, ALP activity, and protein amount) at 152 sites and $\mathrm{Hb}$ amount in GCF of the same site $(P<0.05)$ (Table 3$)$.

\section{Setting of the Hb cutoff value by PD and BOP}

The Hb cutoff value was used to make the ROC curve (Fig. 2) and Youden index. The Hb cutoff value in healthy and diseased paired sites $(n=152)$ in the same oral cavity calculated by PD and BOP was $75.250 \mathrm{ng} /$ pocket (Table 4).

\section{Comparison of parameters in each group reclassified using the $\mathrm{Hb}$ cutoff value}

Clinical parameters (PII, GCF amount, GI, PD, CAL, and ABR ratio) and biochemical parameters (ALP activity and protein amount) in healthy and diseased sites were reclassified by using the $\mathrm{Hb}$ cutoff value showing a high value with the area under the curve and correct diagnosis rate. We then created groups for less than the $\mathrm{Hb}$ cutoff value $(\mathrm{L}-\mathrm{Hb})$ and greater than the $\mathrm{Hb}$ cutoff value $(\mathrm{H}-\mathrm{Hb})$ in healthy and diseased sites (healthy L-Hb/diseased L-Hb groups and healthy $\mathrm{H}-\mathrm{Hb}$ /diseased $\mathrm{H}-\mathrm{Hb}$ groups, respectively). After reclassification of each test result into these four groups, Kruskal-Wallis analysis was carried out to compare parameters between each group, and the results revealed significant differences among groups for all clinical and biochemical parameters $(P<0.01)$.
Fig. 1 Flowchart of $152 \mathrm{GCF}$ samples from 76 patients

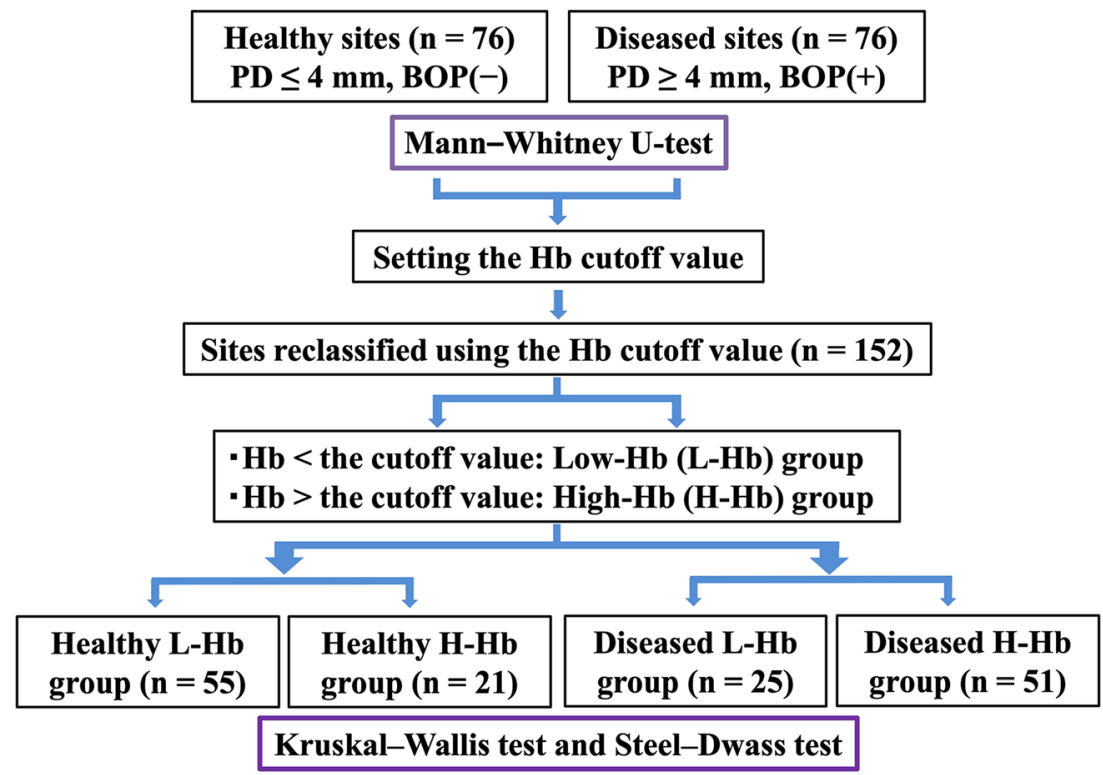


Table 2 Comparison between healthy sites and diseased sites

\begin{tabular}{|c|c|c|c|c|c|}
\hline Clinical and biochemical parameters & Sites & Mean $\pm \mathrm{SD}$ & First quartile & Median & Third quartile \\
\hline \multirow[t]{2}{*}{ PII } & Healthy sites & $0.1 \pm 0.4$ & 0.0 & 0.0 & 0.0 \\
\hline & Diseased sites & $0.6 \pm 0.7^{* * * *}$ & 0.0 & 0.0 & 1.0 \\
\hline \multirow[t]{2}{*}{ GCF amount ( $\mu 1 /$ pocket $)$} & Healthy sites & $0.5 \pm 0.3$ & 0.2 & 0.3 & 0.6 \\
\hline & Diseased sites & $1.3 \pm 0.8^{* * * *}$ & 0.6 & 1.1 & 1.7 \\
\hline \multirow[t]{2}{*}{$\mathrm{PD}(\mathrm{mm})$} & Healthy sites & $2.1 \pm 0.7$ & 2.0 & 2.0 & 2.0 \\
\hline & Diseased sites & $4.9 \pm 1.1^{* * * *}$ & 4.0 & 5.0 & 5.5 \\
\hline \multirow[t]{2}{*}{$\mathrm{CAL}(\mathrm{mm})$} & Healthy sites & $3.1 \pm 1.5$ & 2.0 & 3.0 & 4.0 \\
\hline & Diseased sites & $6.6 \pm 2.1^{* * *}$ & 5.0 & 6.0 & 8.0 \\
\hline \multirow[t]{2}{*}{ GI } & Healthy sites & $0.2 \pm 0.4$ & 0.0 & 0.0 & 0.0 \\
\hline & Diseased sites & $1.3 \pm 0.7^{* * *}$ & 1.0 & 1.0 & 2.0 \\
\hline \multirow[t]{2}{*}{ ABR ratio $(\%)$} & Healthy sites & $15.2 \pm 19.0$ & 0.0 & 9.2 & 27.9 \\
\hline & Diseased sites & $47.0 \pm 23.4^{* * * *}$ & 28.8 & 44.1 & 66.4 \\
\hline \multirow[t]{2}{*}{ ALP activity ( $\mu \mathrm{U} /$ pocket $)$} & Healthy sites & $78.4 \pm 129.6$ & 19.3 & 30.8 & 80.5 \\
\hline & Diseased sites & $445.7 \pm 849.6^{* * * *}$ & 39.0 & 127.5 & 386.1 \\
\hline \multirow[t]{2}{*}{ Protein amount ( $\mu \mathrm{g} /$ pocket) } & Healthy sites & $14.0 \pm 10.3$ & 6.1 & 11.6 & 19.1 \\
\hline & Diseased sites & $33.0 \pm 25.5^{* * *}$ & 16.1 & 25.3 & 39.0 \\
\hline \multirow[t]{2}{*}{$\mathrm{Hb}$ amount (ng/pocket) } & Healthy sites & $51.2 \pm 48.8$ & 7.4 & 35.7 & 86.8 \\
\hline & Diseased sites & $86.5 \pm 43.9^{* * * *}$ & 53.6 & 96.6 & 119.7 \\
\hline
\end{tabular}

Healthy sites $\mathrm{PD} \leq 4 \mathrm{~mm}, \mathrm{BOP}(-) ; n=76$

Diseased sites PD $\geq 4 \mathrm{~mm}, \mathrm{BOP}(+) ; n=76$

**** $P<0.001$ versus healthy sites

Furthermore, the Steel-Dwass test was performed for post hoc testing. A comparison between each parameter level included in the $\mathrm{L}-\mathrm{Hb}$ group and that in the $\mathrm{H}-\mathrm{Hb}$ group at each healthy or diseased site is shown in Table 5.

At healthy sites, ALP activity and protein amount of the H$\mathrm{Hb}$ group were significantly higher than those of the L-Hb group $(P<0.01)$. In contrast, at diseased sites, a significant difference between $\mathrm{L}-\mathrm{Hb}$ and $\mathrm{H}-\mathrm{Hb}$ groups was observed only for protein amount $(P<0.01)$.

However, there were no significant differences between L$\mathrm{Hb}$ and $\mathrm{H}-\mathrm{Hb}$ groups for PII, GCF amount, GI, PD, CAL, and
ABR ratio at healthy sites or PII, GCF amount, GI, PD, CAL, $\mathrm{ABR}$ ratio, and ALP activity at diseased sites.

\section{Discussion}

Current periodontal tissue examinations, i.e., measurement of $\mathrm{PD}, \mathrm{CAL}, \mathrm{BOP}$, and $\mathrm{ABR}$ ratio (clinical parameters), indicate the degree of tissue damage caused by a history of periodontal disease. In particular, BOP is important for maintenance of the attachment position during the SPT

Table 3 Correlation between $\mathrm{Hb}$ amount and clinical and biochemical parameters ( $n=152$ sites)

\begin{tabular}{|c|c|c|c|c|c|}
\hline Clinical and biochemical parameters & Mean \pm SD & Correlation coefficient & First quartile & Median & Third quartile \\
\hline PII & $0.4 \pm 0.6$ & $0.178^{*}$ & 0.0 & 0.0 & 1.0 \\
\hline GCF amount $(\mu 1 /$ pocket $)$ & $0.9 \pm 0.7$ & $0.399^{* * *}$ & 0.3 & 0.6 & 1.2 \\
\hline $\mathrm{PD}(\mathrm{mm})$ & $3.5 \pm 1.6$ & $0.322^{* * * *}$ & 2.0 & 4.0 & 5.0 \\
\hline $\mathrm{CAL}(\mathrm{mm})$ & $4.9 \pm 2.6$ & $0.271^{* * * *}$ & 3.0 & 4.0 & 6.5 \\
\hline GI & $0.7 \pm 0.8$ & $0.365^{* * * *}$ & 0.0 & 1.0 & 1.0 \\
\hline BOP & $0.5 \pm 0.5$ & $0.368^{* * * *}$ & 0.0 & 0.5 & 1.0 \\
\hline ABR ratio $(\%)$ & $31.1 \pm 26.6$ & $0.265^{* * * *}$ & 6.8 & 28.6 & 48.7 \\
\hline ALP activity ( $\mu \mathrm{U} /$ pocket) & $262.1 \pm 633.1$ & $0.407^{* * * *}$ & 22.8 & 64.1 & 174.4 \\
\hline Protein amount ( $\mu \mathrm{g} /$ pocket $)$ & $23.5 \pm 21.6$ & $0.529^{* * * *}$ & 8.8 & 17.1 & 28.6 \\
\hline
\end{tabular}

$\mathrm{Hb}$ amount $=68.9 \pm 49.5 \mathrm{ng} /$ pocket

**** $P<0.001,{ }^{*} P<0.05$ 
$\mathrm{ROC}$ curve of $\mathrm{Hb}$ amount

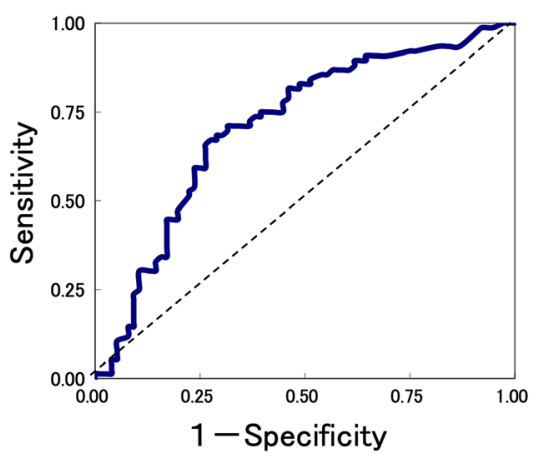

\begin{tabular}{lccc}
\hline & $\begin{array}{c}\text { Diseased } \\
\text { sites }\end{array}$ & $\begin{array}{c}\text { Healthy } \\
\text { sites }\end{array}$ & Total \\
\hline $\mathrm{Hb}>$ cutoff value positive & 51 & 21 & 72 \\
\hline $\mathrm{Hb}<$ cutoff value negative & 25 & 55 & 80 \\
\hline & 76 & 76 & 152
\end{tabular}

Fig. 2 ROC curve and accuracy of the diagnosis

phase. Lang et al. reported that although acquisition of BOP (-) was important for maintaining the attachment position, a case showing attachment loss was slightly observed even in the case of BOP (-) [7]. Now, many reports on GCF components have concluded that the biochemical marker showing a high correlation with periodontal tissue examinations is effective for the onset and progression of periodontal disease [8]. In contrast, we speculated that detection of weak tissue damage in BOP $(-)$ periodontal tissue can indicate premature periodontal disease.

Periodontal disease progression can be estimated by not only the presence of oral bacteria such as Porphyromonas gingivalis and Treponema denticola in GCF and saliva but also biochemical parameters in combination with clinical parameters [29-32]. In particular, measurements of matrix metalloproteinases, ALP, alanine aminotransferase and, $\mathrm{Hb}$ amount as biochemical parameters in GCF have gained

Table 4 Cutoff value for $\mathrm{Hb}$

\begin{tabular}{ll}
\hline Statistical indicators & Indicator value \\
\hline Cutoff value & 75.25 (ng/pocket) \\
Area under the curve & 0.712 \\
Sensitivity & 0.671 \\
Specificity & 0.724 \\
Positive predictive value & 0.708 \\
Negative predictive value & 0.688 \\
Proper diagnosis rate & 0.697 \\
Likelihood ratio & 2.431 \\
\hline
\end{tabular}

Analysis results using the ROC curve for healthy sites (defined as $\mathrm{PD} \geq$ $4 \mathrm{~mm}, \mathrm{BOP}(-) ; n=76$ ) and diseased sites (defined as $\mathrm{PD} \leq 4 \mathrm{~mm}$, BOP $(+) ; n=76)$ attention, and clinical application of these tests is being studied $[8,10,15,16,31]$.

We previously reported that $\mathrm{Hb}$ was observed in $>60 \%$ of GCF of 176 BOP (-) sites in 229 gingival sulci of 184 nonsmokers who were under regular SPT [10]. This result suggested that the inspection of $\mathrm{Hb}$ derived from microbleeding in gingival sulci may serve as an index for preclinical diagnosis. In this study, the amount of $\mathrm{Hb}$ in GCF of 152 sites strongly correlated with all clinical parameters evaluated (PII, GCF amount, GI, PD, CAL, BOP, and ABR ratio), as well as biochemical parameters (ALP activity and protein amount) (Table 3).

To examine whether periodontal disease progression can be accurately determined by $\mathrm{Hb}$ examination, healthy sites (PD $\leq 4 \mathrm{~mm}, \mathrm{BOP}(-))$ and diseased sites (PD $\geq 4 \mathrm{~mm}$, BOP $(+))$ in the same oral cavity of SPT patients were reclassified into four groups using the $\mathrm{Hb}$ cutoff value. Then, clinical and biochemical parameters between these four groups were compared. All clinical and biochemical parameters in diseased sites were higher than those in healthy sites in the same oral cavity (Table 5). In contrast, ALP activity and protein amount, which increase with periodontitis, were significantly higher in the healthy $\mathrm{H}-\mathrm{Hb}$ group $(117.31 \pm 150.18 \mu \mathrm{U} /$ pocket and $19.84 \pm 12.38 \mu \mathrm{g} /$ pocket, respectively) than in the healthy L$\mathrm{Hb}$ group $(63.60 \pm 118.98 \mu \mathrm{U} /$ pocket and $11.74 \pm 8.53 \mu \mathrm{g} /$ pocket, respectively) $(P<0.01)$. These results indicated that slight tissue damage may have occurred even in healthy gingival sulcus as defined by BOP and PD measurements. Moreover, our findings suggest that $\mathrm{Hb}$ examination is a promising candidate marker in the initial condition of periodontal disease.

The method used for quantification of $\mathrm{Hb}$ in GCF in this study is based on the IC method using human $\mathrm{Hb}$ monoclonal antibody, and it can be carried out with high accuracy and short chairside time [10]. Therefore, $\mathrm{Hb}$ examination of GCF may capture periodontal disease in the initial state and become a powerful diagnostic tool for pre-symptomatic diagnosis. However, this investigation was a cross-sectional study and only mentioned the possibility of pre-symptomatic diagnosis. Therefore, it is necessary to verify not only the longterm prognosis but also the effects of past treatment history. In addition, these findings must be confirmed using a marker such as matrix metalloproteinase-8 [33] that is effective for the pre-symptomatic diagnosis of periodontal disease. We believe that the key for pre-symptomatic diagnosis is the detection of specific biochemical markers observed in GCF that fluctuate during BOP (-). In this study, during periodontal tissue stabilization showing BOP (-), ALP activity and protein amount indicating tissue damage were also significantly increased when $\mathrm{Hb}$ was significantly increased. It is urgently necessary to create a standard $\mathrm{Hb}$ value in GCF with high sensitivity and specificity to indicate periodontal tissue damage for pre-symptomatic diagnosis of periodontal disease. 
Table 5 Comparison among healthy low-Hb cutoff group (healthy L-Hb group), healthy high-Hb cutoff group (healthy $\mathrm{H}-\mathrm{Hb}$ group), diseased low- $\mathrm{Hb}$ cutoff group (diseased L-Hb group), and diseased high-Hb cutoff group (diseased $\mathrm{H}-\mathrm{Hb}$ group)

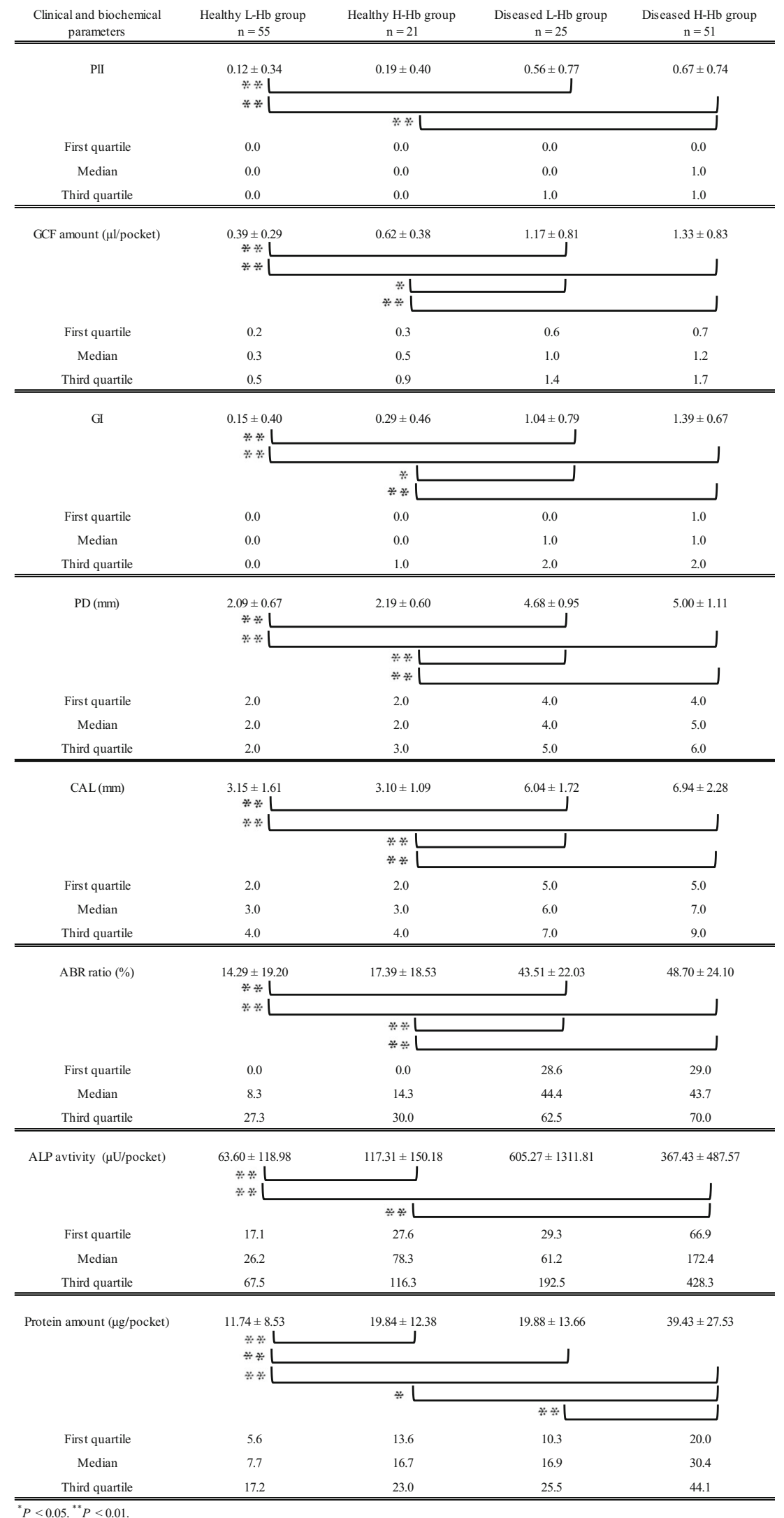




\section{Conclusion}

In this study, $\mathrm{Hb}$ examination in GCF detected slight tissue damage even in clinically periodontal healthy sites. These results suggest that $\mathrm{Hb}$ examination is a promising candidate marker for the pre-symptomatic state in periodontal disease.

Acknowledgments We thank Syun-ichi Abe (Yamate Information Processing Center Ltd., Tokyo, Japan) for advice regarding statistical analysis.

Funding information This study was supported by Grants-in-Aid from the Ministry of Education and Science Research Funds (Grant Nos. 20K09964 and 20K09981) and a grant from the "New medical equipment and technology industry vision" project of the Japan Dental Association.

\section{Compliance with ethical standards}

This study was conducted in accordance with the Helsinki Declaration of 1975, as revised in 2013, with approval from the ethics committee of the Nippon Dental University Hospital (Approval Nos. NDU-T 2017-12 and NDUH-RINRI2018-07).

Conflict of interest The authors declare that they have no conflict of interest.

Disclaimer The authors alone are responsible for the content and writing of this manuscript. Drs.Ito, Numabe, and Hashimoto have applied for a patent on the IC method applied to periodontal diagnosis described in this research (No. 2013-257312).

Open Access This article is licensed under a Creative Commons Attribution 4.0 International License, which permits use, sharing, adaptation, distribution and reproduction in any medium or format, as long as you give appropriate credit to the original author(s) and the source, provide a link to the Creative Commons licence, and indicate if changes were made. The images or other third party material in this article are included in the article's Creative Commons licence, unless indicated otherwise in a credit line to the material. If material is not included in the article's Creative Commons licence and your intended use is not permitted by statutory regulation or exceeds the permitted use, you will need to obtain permission directly from the copyright holder. To view a copy of this licence, visit http://creativecommons.org/licenses/by/4.0/.

\section{References}

1. Lang NP, Matulien G, Salvi GE, Tonetti MS (2015) Supportive periodontal therapy. In: Lang NP, Lindhe J (eds) Clinical periodontology and implant dentistry, 6th edn. Wiley, UK, pp 1347-1371

2. Robert LM (2019) Supportive Periodontal Treatment. In: Newman MG, Takei HH, Klokkevold PR, Carranza FA (eds) Clinical periodontology, 13th edn. Elsevier, Philadelphia, pp 714-723

3. Armitage GC, Svanberg GK, Löe H (1977) Microscopic evaluation of clinical measurements of connective tissue attachment levels. J Clin Periodontol 4:173-190. https://doi.org/10.1111/j.1600-051X. 1977.tb02271.x

4. Listgarten MA (1980) Periodontal probing: what does it mean? J Clin Periodontol 7:165-176. https://doi.org/10.1111/j.1600-051X. 1980.tb01960.x
5. Fowler C, Garrett S, Crigger M, Egelberg J (1982) Histologic probe position in treated and untreated human periodontal tissues. J Clin Periodontol 9:373-385. https://doi.org/10.1111/j.1600-051X.1982. tb02048.x

6. Heft MW, Perelmuter SH, Cooper BY, Magnusson I, Clark WB (1991) Relationship between gingival inflammation and painfulness of periodontal probing. J Clin Periodontol 18:213-215. https://doi.org/10.1111/j.1600-051X.1991.tb01137.x

7. Lang NP, Adler R, Joss A, Nyman S (1990) Absence of bleeding on probing. An indicator of periodontal stability. J Clin Periodontol 17: 714-721. https://doi.org/10.1111/j.1600-051X.1990.tb01059.x

8. Loss BG, Tjoa S (2005) Host-derived diagnostic markers for periodontitis: do they exist in gingival crevice fluid? Periodontology 2000 39:53-72. https://doi.org/10.1111/j.1600-0757.2005.00129.x

9. Ito H, Numabe Y, Hashimoto S et al (2014) Evaluation of bleeding on probing and gingival crevicular fluid enzyme activity for detection of periodontally active sites during supportive periodontal therapy. Odontology 102:50-56. https://doi.org/10.1007/s10266-0120090-1

10. Ito $\mathrm{H}$, Numabe $\mathrm{Y}$, Hashimoto $\mathrm{S}$, Sekino $\mathrm{S}$, Murakashi E, Ishiguro H, Sasaki D, Yaegashi T, Takai H, Mezawa M, Ogata Y, Watanabe H, Hagiwara S, Izumi Y, Hiroshima Y, Kido JI, Nagata T, Kunimatsu K (2016) Correlation between gingival crevicular fluid hemoglobin content and periodontal clinical parameters. J Periodontol 87:1314-1319. https://doi.org/10.1902/jop.2016. 160092

11. Ainamo J, Bay I (1975) Problems and proposals for recording gingivitis and plaque. Int Dent J 25:229-235

12. Greenstein G, Caton J, Polson AM (1981) Histologic characteristics associated with bleeding after probing and visual signs of inflammation. J Periodontol 52:420-425. https://doi.org/10.1902/jop. 1981.52.8.420

13. Uehara S, Ito H, Hashimoto S, Numabe Y (2018) Relationship between bone-type alkaline phosphatase levels in gingival crevicular fluid and clinical parameters during supportive periodontal therapy. J Jpn Soc Periodontol 60:26-34. https://doi.org/10.2329/perio. 60.26

14. Bessey OA, Lowry OH, Brock MJ (1946) A method for the rapid determination of alkaline phosphatase with five cubic millimeters of serum. J Biol Chem 164:321-329

15. Chapple IL, Gainer I, Saxby MS, Moscrop H, Matthews JB (1999) Prediction and diagnosis of attachment loss by enhanced chemiluminescent assay of clavicular fluid alkaline phosphatase levels. J Clin Periodontol 26:190-198. https://doi.org/10.1034/j.1600051X.1999.260310.x

16. Gupta S, Chhina S, Arosa SA (2018) A systematic review of biomarkers of gingival crevicular fluid: their predictive role in diagnosis of periodontal status. J Oral Biol Craniofac Res 8:98-104. https://doi.org/10.1016/j.jobcr.2018.02.002

17. Bickel M, Cimasoni G, Anderson E (1985) Flow and albumin content of early (pre-inflammatory) gingival crevicular fluid from human subjects. Arch Oral Biol 30:599-602. https://doi.org/10.1016/ 0003-9969(85)90079-2

18. Adonogianaki E, Mooney J, Kinane DF (1996) Detection of stable and active periodontitis sites by clinical assessment and gingival crevicular acute-phase protein levels. J Periodontal Res 31:135143. https://doi.org/10.1111/j.1600-0765.1996.tb00475.x

19. Kardeșler L, Buduneli N, Çetinkalp Ș, Lappin D, Kinane DF (2011) Gingival crevicular fluid IL-6, tPA, PAI-2, albumin levels following initial periodontal treatment in chronic periodontitis patients with or without type 2 diabetes. Inflamm Res 60:143-151. https:// doi.org/10.1007/s00011-010-0248-7

20. Maurizio ST, Henry G, Kenneth SK (2018) Staging and grading of periodontitis: framework and proposal of a new classification and case definition. J Clin Periodontol 45(Suppl):S149-S161. https:// doi.org/10.1111/jcpe. 12945 
21. Lang NP, Joss A, Orsanic T, Gusberti FA, Siegrist BE (1986) Bleeding on probing. A predictor for progression of periodontal disease? J Clin Periodontol 13:590-596. https://doi.org/10.3109/ 00016356408993968

22. Claffey N, Nylund K, Kiger R, Garrett S, Egerberg J (1990) Diagnostic predictability of score plaque, bleeding, suppuration and probing depth for attachment loss. $31 / 2$ years of observation following initial periodontal therapy. J Clin Periodontol 17:108114. https://doi.org/10.1111/j.1600-051X.1990.tb01071.x

23. Matuliene G, Pjetursson BE, Salvi GE, Schmidlin K, Brägger U, Zwahlen M, Lang NP (2008) Influence of residual pockets on progression and tooth loss: results after 11 years of maintenance. J Clin Periodontol 35:685-695. https://doi.org/10.1111/j.1600-051X. 2008.01245.x

24. Silness J, Löe H (1964) Periodontal disease in pregnancy II. Correlation between oral hygiene and periodontal condition. Acta Odontol Scand 22:112-135. https://doi.org/10.3109/ 00016356408993968

25. Löe H (1967) The gingival index, the plaque index and the retention index systems. J Periodontol 38:610-616. https://doi.org/10.1902/ jop.1967.38.6 part2.610

26. Schei O, Waerhaug J, Lovdal A, Arno A (1959) Alveolar bone loss as related to oral hygiene and age. J Periodontol 30:7-16. https:// doi.org/10.1902/jop.1959.30.1.7

27. Mizuike R, Sasaki T, Baba H et al (2011) Development of two types of rapid diagnostic test kits to detect the hemagglutinin or nucleoprotein of the swine-origin pandemic influenza a virus H1N1. Clin Vaccine Immunol 18:494-499 https://cvi.asm.org/ content/18/3/494.long

28. Sasaki T, Kubota-Koketsu R, Takei M, Hagihara T, Iwamoto S, Murao T, Sawami K, Fukae D, Nakamura M, Nagata E, Kawakami A, Mitsubayashi Y, Ohno M, Uehara Y, Fukukawa T, Kanai Y, Kosaka M, Ikuta K (2012) Reliability of a newlydeveloped immunochromatography diagnostic kit for pandemic influenza a/h1n1pdm virus: implications for drug administration. PLoS One 7:e50670. https://doi.org/10.1371/journal.pone.0050670

29. Morozumi T, Nakagawa T, Nomura Y, Sugaya T, Kawanami M, Suzuki F, Takahashi K, Abe Y, Sato S, Makino-Oi A, Saito A, Takano S, Minabe M, Nakayama Y, Ogata Y, Kobayashi H, Izumi $\mathrm{Y}$, Sugano $\mathrm{N}$, Ito $\mathrm{K}$, Sekino $\mathrm{S}$, Numabe $\mathrm{Y}$, Fukaya $\mathrm{C}$, Yoshinari N, Fukuda M, Noguchi T, Kono T, Umeda M, Fujise O, Nishimura F, Yoshimura A, Hara Y, Nakamura T, Noguchi K, Kakuta E, Hanada N, Takashiba S, Yoshie H (2016) Salivary pathogen and serum antibody to assess the progression of chronic periodontitis: a 24-mo prospective multicenter cohort study. J Periodontal Res 51:768-778. https://doi.org/10.1111/jre.12353

30. Brrne SJ, Daspher SG, Darby IB, Adams GG, Hoffmann B, Reynolds EC (2009) Progression of chronic periodontitis can be predicted by the levels of Porphyromonas gingivalis and Treponema denticola in subgingival plaque. Oral Microbiol Immunol 24:469-477. https://doi.org/10.1111/j.1399-302X.2009. 00544.x

31. Kinney JS, Morelli T, Oh M, Braun TM, Ramseier CA, Sugai JV, Giannobile WV (2014) Crevicular fluid biomarkers and periodontal disease progression. J Clin Periodontol 41:113-120. https://doi.org/ $10.1111 /$ jcpe. 12194

32. Nomura Y, Shimada Y, Hanada N, Numabe Y, Kamoi K, Sato T, Gomi K, Arai T, Inagaki K, Fukuda M, Noguchi T, Yoshie H (2012) Salivary biomarkers for predicting the progression of chronic periodontitis. Arch Oral Biol 57:413-420. https://doi.org/10. 1016/j.archoralbio.2011.09.011

33. Ahmed AM, Saeed A, Nilminie R, Taina T, Dirk-Rolf G, Timo S (2018) Matrix metalloproteinase- 8 as an inflammatory and prevention biomarker in periodontal and peri-implant diseases. Int J Dent 2018:1-27. https://doi.org/10.1155/2018/7891323

Publisher's note Springer Nature remains neutral with regard to jurisdictional claims in published maps and institutional affiliations. 